\title{
The effects of ankaferd blood stopper and microporous polysaccharide hemospheres on epidural fibrosis in rat laminectomy model ${ }^{1}$
}

\author{
Rafet Özay', Osman Yüksel Yavuz ${ }^{I I}$, Mehmet Erhan Türkoğlu' ${ }^{I}$ Abit Aktaş ${ }^{\mathrm{III}}$, Funda Yiğit ${ }^{\mathrm{IV}}$, Hacı Mustafa Özdemir ${ }^{\mathrm{V}}$, Zeki \\ Şekerci $^{\mathrm{VI}}$
}

DOI: http://dx.doi.org/10.1590/S0102-865020150120000002

${ }^{\mathrm{I}} \mathrm{MD}$, TC. Ministry of Health Diskapi Yildirim Beyazit Training and Research Hospital, Ankara, Turkey. Conception of the study; acquisition, interpretation and analysis of data; manuscript writing.

${ }^{I} \mathrm{MD}$, Department of Orthopedics and Traumatology, Faculty of Medicine, Turgut Ozal University, Ankara, Turkey. Conception of the study; acquisition, interpretation and analysis of data; manuscript writing.

IIIPhD, Associate Professor, Department of Histology and Embryology, Faculty of Veterinary Medicine, Istanbul University, Turkey. Conception of the study; acquisition, interpretation and analysis of data; histophatological examinations; manuscript writing.

${ }^{\mathrm{IV}} \mathrm{PhD}$, Researcher, Department of Histology and Embryology, Faculty of Veterinary Medicine, Istanbul University, Turkey. Histophatological examinations.

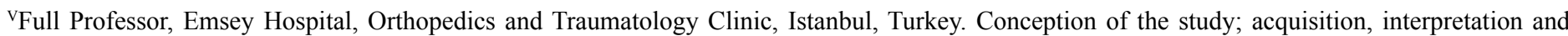
analysis of data; manuscript writing; critical revision.

${ }^{\mathrm{VII}}$ Full Professor, TC, Ministry of Health Diskapi Yildirim Beyazit Training and Research Hospital, Ankara, Turkey. Conception of the study; acquisition, interpretation and analysis of data; manuscript writing; critical revision.

\section{ABSTRACT}

PURPOSE: To investigate whether topically administered hemostatic agents ankaferd blood stopper and microporous polysaccharide hemospheres can decrease epidural fibrosis after laminectomy in rats.

METHODS: Eighteen adult male Sprague-Dawley rats were equally and randomly divided into three groups. In the treatment groups, ankaferd blood stopper and microporous polysaccharide hemospheres topically administrated upon duramater surface after laminectomy. Fibroblast count, epidural fibrosis and arachnoidal involvement were evaluated and graded histopathologically.

RESULTS: Our data revealed that the count of fibroblasts, the grading of epidural fibrosis and arachnoideal involvement in the rats treated with microporous polysaccharide hemospheres were significantly less than the control group. Although the arachnoideal involvement in ankaferd blood stopper group were significantly less than the control group, there were no statistical differences when comparing the grading of epidural fibrosis and the fibroblasts count between the treatment groups and the control group.

CONCLUSION: The ankaferd blood stopper and microporous polysaccharide hemospheres reduced epidural fibrosis and arachnoideal involvement after laminectomy in rats.

Key words: Fibrosis. Laminectomy. Polysaccharides. Hemostasis. Rats. 


\section{Introduction}

Surgery for lumbar disc herniations are performed over than one million patients all over the world in every year ${ }^{1-2}$. Unsatisfactory result rates according to failed back syndrome are 8 to $25 \%$ of the patients ${ }^{3-4}$. The causes of failed back syndrome are diskectomy for wrong level, recurrent or persistent disc herniation, iatrogenic instability, central or lateral stenosis, arachnoiditis, and spinal epidural fibrosis ${ }^{3-5}$. Spinal epidural fibrosis (EF) is one of the major causes (10-24\%) of failed back syndrome. The average incidence of EF in the MRI series is $16.1 \%$, whereas the incidence $(83.3 \%)$ is definitely higher in the epiduroscopy series ${ }^{6}$.

Epidural fibrosis cause nerve root traction, restricting of nerve root movements, extradural compression, and decreases the arterial supply of the nerve root. Impaired axoplasmic transport and excretion of inflammatory mediators following the decreasing of arterial supply lead to intractable radicular pain ${ }^{1,3,5,7}$. Both back and radicular pain associated with the EF are resistant to physical, medical and surgical treatments ${ }^{1-8}$. Epidural fibrosis is also associated with an increased complication rate in revision spine surgery ${ }^{9,10}$.

Epidural fibrosis is a part of the physiological tissue response after laminectomy. Histologic studies have demonstrated that destruction of epidural fat, epidural hematoma accumulation and muscle invasion of the laminectomy site are the main responsible factors for the formation of dense EF. The destruction of epidural fat results that duramater is exposed to neighboring structures and create a cavity where blood refill as hematoma. If the hematoma is more extensive, this may also cause more dense and thicker scar adhesions throughout inducing the invasion of fibrous tissue elements by the erector spine muscles ${ }^{6,8,10}$. Regarding to hypothesis, the inadequate control of epidural bleeding during surgical interventions is strongly associated with epidural fibrosis ${ }^{4,5,10}$.

The aim of this study is to investigate topically administered hemostatic agents, Ankaferd Blood Stopper (ABS) and Microporous Polysaccharide Hemospheres (MPH) can prevent epidural fibrosis and reduce arachnoideal involvement in a rat laminectomy model.

\section{Methods}

All experimental procedures were approved by the Animal Research Ethical Committee of Gazi University and the study was carried out at the Animal Breeding and Experimental Research Laboratory Center of Gazi University.

\section{Surgical procedure and sample preparation}

The surgical procedures were performed under general anesthesia. Rats were sedated with $5 \mathrm{mg} / \mathrm{kg}$ of Xylazine hydrochloride (Rompun/Bayer/Turkey) intraperitoneally (ip) and anesthetized with $45 \mathrm{mg} / \mathrm{kg}$ ketamine hydrochloride ip (Ketalar / Eczacıbaş//Turkey). Rats were stabilized on the operation table in a prone position after deep anesthesia. The lower back of each rat, which is the surgical site, was sterilized with povidone. Following sterile isolation, long posterior midline surgical incisions were performed between the L4 and L6 levels. The lumbar fascia was opened approximately $2-2.5 \mathrm{~cm}$ over the spinous processes. Bilaterally, the paravertebral muscles were subperiostally dissected to expose the L34-6 laminae. A total L5 laminectomy and flavectomy were performed, and epidural fat tissues were removed, leaving the duramater clean and fully exposed. The rats were then randomly allocated into three groups with six rats per group. After treatment, the wounds were primarily sutured in anatomical layers (Prolen polypropylene sutures, Ethicon, Ethicon Endo-Surgery, Inc., Cincinnati, OH, USA). All surgical procedures were done under $\mathrm{x} 4$ optical magnification (Carl-Zeiss Opmı 9-FC 293191, Germany) and performed by the first author (RO). The rats had been then released for free food and water consumption for six weeks. After six weeks, the rats were sacrificed with the administration of intraperitoneal high dose thiopental sodium (Pental, Ulagay, İstanbul-Turkey, 2007) solution (10 mg/kg). The vertebral columns of the rats (L4-6) were removed en bloc, including the whole laminectomy area, dural sacs, nerve roots, and paravertebral soft tissues. The specimen was then placed into $10 \%$ buffered formalin

\section{Experimental groups}

Adult male Sprague-Dawley rats weighing 250-300g were used in this study.

Control group $(n=6)$ : A laminectomy was performed and the surgical site was irrigated with saline solution (Eczacıbaşı, Turkey). Hemostasis had been achieved using cotton pad compression for several minutes. Any other hemostatic materials and bipolar cauterization were not applied.

ABS group $(n=6)$ : ABS (Ankaferd Blood Stopper ${ }^{\circledR}$; ABS; Ankaferd Health Products Ltd., Istanbul, Turkey) 1 cc (Urtica dioica: $0.6 \mathrm{mg}$, Vitis vinifera: $0.8 \mathrm{mg}$, Glycrrhiza glabra: $0.9 \mathrm{mg}$, Alpinia officinarum: $0.7 \mathrm{mg}$, Thymus vulgaris: $0.5 \mathrm{mg}$ ) was poured on the surface of the laminectomy site for hemostasis 
and any other hemostatic materials and bipolar cauterization were not applied.

MPH group (n=6): MPH (Arista ${ }^{\mathrm{TM}}$; Medafor Inc, Minneapolis, $\mathrm{MN}$ ) powder was filled adequately the surface of the laminectomy site for hemostasis. Any other hemostatic materials and bipolar cauterization were not applied.

\section{Histological analysis}

The specimen had been decalcified in a De Castro solution (mixture: $300 \mathrm{ml}$ of ethanol, $50 \mathrm{~g}$ of chloral hydrate, $670 \mathrm{ml}$ of distilled water, $30 \mathrm{ml}$ of $70 \%$ nitric acid) for 10 days ${ }^{11}$. After complete decalcification, the specimens were dehydrated and embedded in paraffin $5 \mu \mathrm{m}$ thick sections obtained from previously prepared paraffin blocks that were subjected to hematoxylin and eosin (H\&E) staining and Masson's trichrome. The specimens were examined under a light microscope. Grading of EF and arachnoidal involvement was performed according to the definition of He et al. ${ }^{12}$ (Table 1). The histological examination was conducted in a blinded manner by an experience examiner.

TABLE 1 - Grading of the epidural fibrosis and arachnoidal involvement.

\begin{tabular}{|c|c|c|}
\hline Grade & Arachnoidal involvement & Epidural fibrosis \\
\hline Grade 0 & Undetectable & The dura is free of scar tissue \\
\hline Grade 1 & Minimal & Only thin fibrous bands are observed between the scar tissue and dura \\
\hline Grade 2 & Moderate & $\begin{array}{l}\text { Continuous adherence is observed in less than two-thirds of } \\
\text { the laminectomy defect }\end{array}$ \\
\hline Grade 3 & Severe & $\begin{array}{c}\text { Scar tissue adherence is large, affecting }>\text { two-thirds of the laminectomy } \\
\text { defect }\end{array}$ \\
\hline
\end{tabular}

To determine the number of fibroblasts taken from the three separate sections on each laminectomized spine, three distinct regions on the surface area were determined as $100.000 \mu^{2}$. Six different areas were counted on each animal, and stereological analyses of fibroblasts were conducted according to the studies described previously ${ }^{13-14}$. A stereological workstation composed of a digital camera (mbf/Bioscience, Qimaging), automatic controlled specimen stage, a light microscope (Leica, DM400B), and a software program (mbf Bioscience, Stereo investigator, version 9) were used to count fibroblasts. Therefore, we chose an area fraction approach with an area of an unbiased counting frame of $900 \mu \mathrm{m}^{2}$. Meander sampling of each sectioned fibroblast was done in a $70 \mu \mathrm{m} \times 70 \mu \mathrm{m}$ step size in a systematic-random manner. For each animal, the number of fibroblasts in the selected areas listed was adapted by one $\mathrm{mm}^{2}$.

\section{Statistical analysis}

Data analysis was performed by using SPSS for Windows, version 20.0 (SPSS Inc., Chicago, IL, United States). Whether the distributions of continuous variables were normally or not was determined by using Kolmogorov-Smirnov test. Data were shown as mean $\pm \mathrm{SD}$, where applicable.
The mean differences among groups were analyzed by One-Way ANOVA. When the $\mathrm{p}$ value from One-Way ANOVA are statistically significant, post hoc LSD were used to know which group differ from others. Chi-squared test was used for analysis of nominal (categorical) data. If $\mathrm{p}$ value less than 0.05 , it was considered as statistically significant.

\section{Results}

\section{Wound healing and complications}

ABS and MPH did not affect wound healing in any rats. We did not observe any wound infection, abnormal foreignbody reaction, abscess formation, hematoma, or CSF leakages. All animals were ambulatory at the time of sacrification.

\section{Assessment of the count of fibroblasts}

The count of fibroblast results were calculated as 984.166 \pm 245.996 in the control group, $706.666 \pm 163.666$ in the ABS group, and $545.833 \pm 183.014$ in MPH group. The differences of fibroblasts count between MPH and control groups were 
statistically significant $(p=0.002)$. The differences of fibroblasts count between ABS and the control groups were also statistically significant $(\mathrm{p}=0.030)$. These results indicate that both MPH and
ABS groups had a decreased count of fibroblasts when compared to control group (Table 2) (Figures 1B, 2B and 3B).

TABLE 2 - Result of histological analysis; the count of fibroblasts, epidural fibrosis score and arachnoidal involvement.

\begin{tabular}{ccccc}
\hline Histological analysis & Control group & MPH group & ABS group \\
\hline The count of fibroblasts & $984.16 \pm 245.996$ & $545.83 \pm 183.014$ & $706.66 \pm 163.666$ & $\mathrm{P}^{1}: 0.002, \mathrm{P}^{2}: 0.030, \mathrm{P}^{3}: 0.065$ \\
$\begin{array}{c}\text { Epidural fibrosis score } \\
\text { Arachnoidal involvement } \\
\text { score }\end{array}$ & $2.33 \pm 0.51$ & $1.33 \pm 0.51$ & $1.66 \pm 0.81$ & $\mathrm{P}^{1}: 0.036, \mathrm{P}^{2}: 0.135, \mathrm{P}^{3}: 0.465$ \\
\hline
\end{tabular}

MPH; ABS; Ankaferd Blood Stopper, MPH; Microporous Polysaccharide Cont\&MPH: P1, Cont\&ABS:P2, MPH\&ABS: $\mathrm{P}^{3}$

Hemospheres, P; P value

\section{Assessment of EF}

The grading of EF was detected as $2.33 \pm 0.51$ in the control group, $1.66 \pm 0.81$ in the ABS group, and $1.33 \pm 0.51$ in the MPH group. Epidural fibrosis in the MPH group was markedly lower than the control group and showed statistically significant differences $(p=0.036)$. However, there was no statistically significant difference between the ABS and control groups $(p=$ 0.135) (Table 2) (Figures 1A, 2A and 3A).

\section{Assessment of arachnoidal involvement}

The gradings of arachnoidal involvement were detected as $2.33 \pm 0.51$ in the control group, $1.50 \pm 0.54$ in the ABS group, and $1.33 \pm 0.75$ in the MPH group. The differences in the grading of arachnoidal involvement between the MPH and control groups were statistically significant $(\mathrm{p}=0.036)$. Although there was no statistically significant difference, ABS group has a lower grade of AI compared to control group $(\mathrm{p}=0.076)$. These results indicate that both the MPH and ABS groups had an attenuated grade of arachnoidal involvement compared to control group (Table 2) (Figures 1A, 2A and 3A).

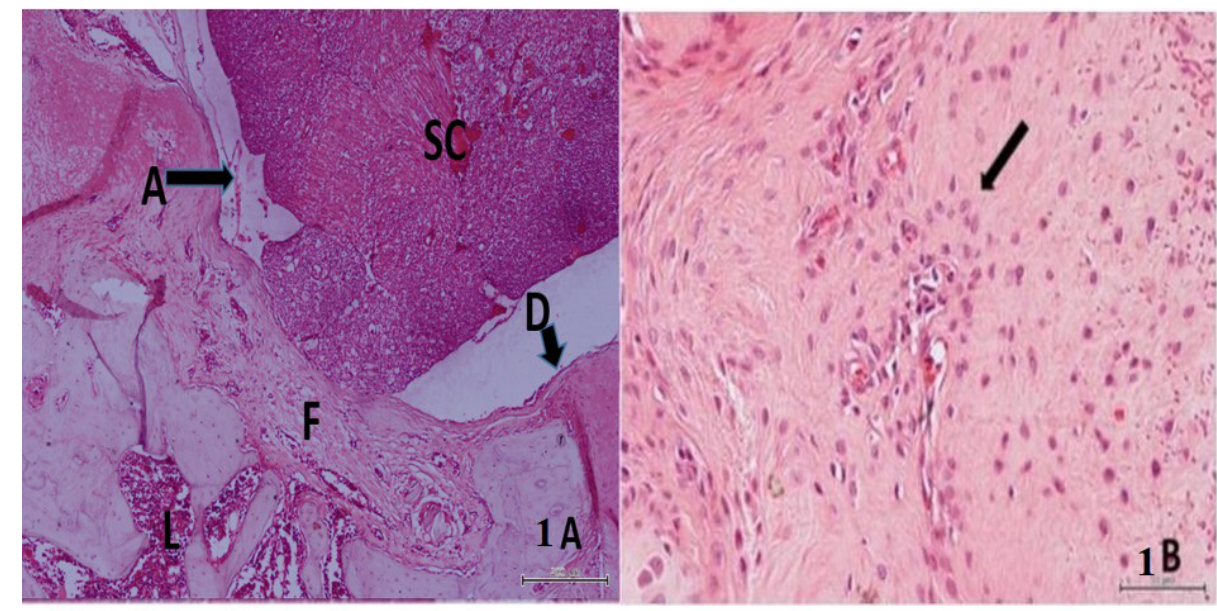

FIGURE 1 - A. Photomicrographs demonstrating fibrosis in the control group. Direct contact between the underlying spinal cord (SC) and the epidural fibrosis tissue (F) is evident. L: Lamina; D: Dura mater, A: Arachnoid mater, Hemotoxylin \& Eosin, Bar: $200 \mu \mathrm{m}$. B. Fibroblast density, note the increased number of fibroblast cells, Black Arrow: Fibroblast, H\&E Bar: $50 \mu \mathrm{m}$ 


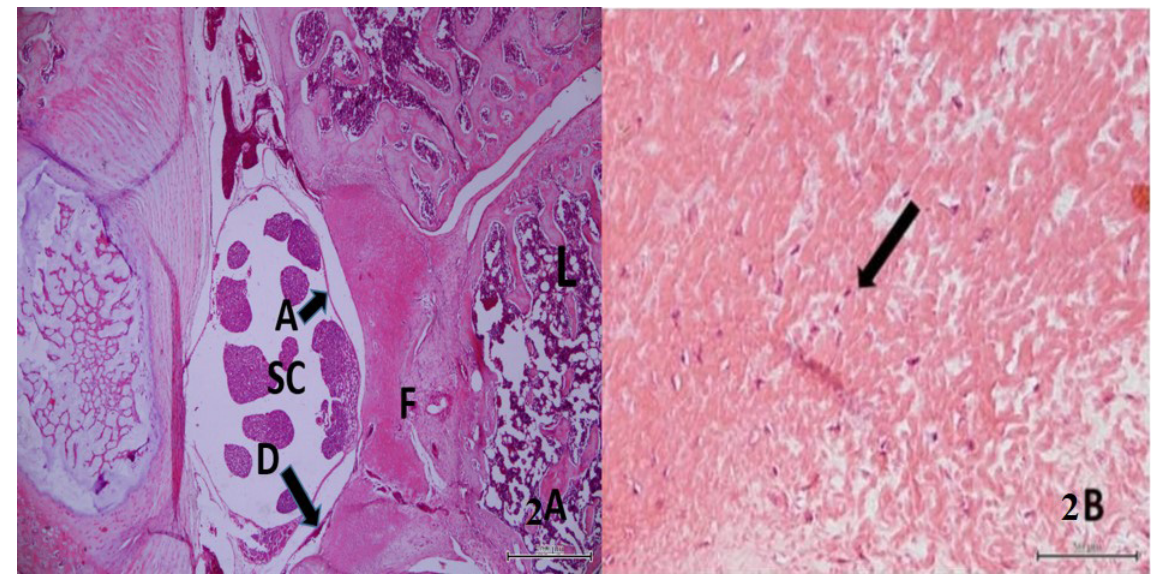

FIGURE 2 - A. Photomicrographs demonstrating fibrosis in the MPH group. No direct contact between the underlying spinal cord (SC) and the epidural fibrosis tissue (F) is evident. L: Lamina; D: Dura mater, A: Arachnoid mater, Hemotoxylin \& Eosin, Bar: $500 \mu \mathrm{m}$. B. Fibroblast density, note the lower number of fibroblast cells, Black Arrow: Fibroblast, H\&E Bar: $50 \mu \mathrm{m}$

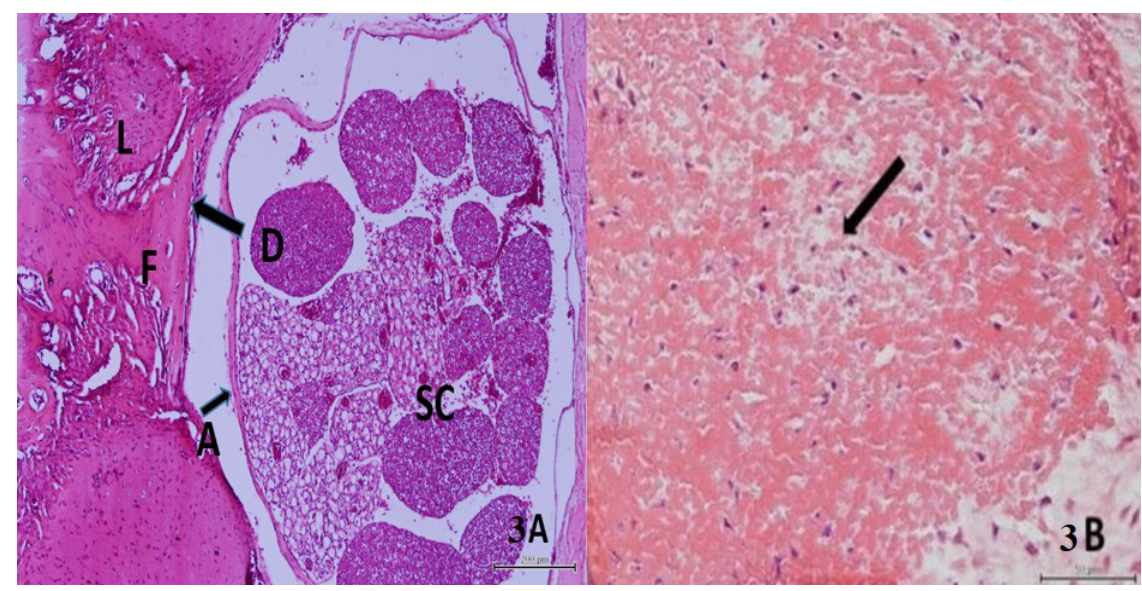

FIGURE 3 - A. Photomicrographs demonstrating fibrosis in the ABS group. No direct contact between the underlying spinal cord (SC) and the epidural fibrosis tissue (F) is evident. L: Lamina; D: Dura mater, A: Arachnoid mater, Hemotoxylin \& Eosin, Bar: $500 \mu \mathrm{m}$. B. Fibroblast density, note the average number of fibroblast cells, Black Arrow: Fibroblast, H\&E Bar: $50 \mu \mathrm{m}$

\section{Discussion}

Quantitative features of the formal characteristics at the fibrous tissue, such as number of fibroblasts, are usually parameters for determining density of epidural fibrosis. Stereological methods are commonly used in research of the fibroblast regarding to experimental peripheral nerve injuries model, and it was showed that the stereological analysis techniques can supply correct and trustworthy estimates of fibroblast count and epidural fibrosis ${ }^{15-16}$. Previous studies suggested that the fibroblast cells in the fibrous tissue should be counted in three different areas, expressed as a mean value, and the fibroblast densities should be graded ${ }^{17}$. In our study, to determine the number of fibroblasts, we performed a stereological morphometric analysis of the fibroblast densities for three separate sections and six different areas were counted on each animal. To the best of our knowledge, this is the first report about the stereological analyses of fibroblasts for the evaluation of the EF after laminectomy in the literature.

The first step for decreasing EF is achieving adequate hemostasis in surgical site. Bipolar coagulation and cotton are broadly using for hemostasis. However, cotton and coagulation on the surgical site may cause additional fibrosis and adhesion formation ${ }^{18-19}$. Although both the introduction of microsurgical techniques and improvements in bipolar coagulation technology ease to hemostasis, EF after laminectomy can still occur ${ }^{4,5,20}$. To overcome this problem, several topical hemostatic agents were developed to prevent bleeding and achieve adequate hemostasis ${ }^{6,20-22}$. Hemostatic agents are more useful especially in the case of ooze bleeding with the risk of postoperative hematoma related to extensive EF. Hemostatic agents using in neurosurgical 
interventions must have a strong hemostatic efficacy to provide durable hemostasis and also be degraded rapidly without tissue reaction or inflammation ${ }^{3,21,23}$.

Microporous Polysaccharide Hemospheres (Arista; Medafor, Inc., Minneapolis, MN) is a novel hemostatic agent made from plant starch. It is formed into tightly engineered microporous particles with porosity and spherical diameters and was recently approved by the Food and Drug Administration for internal use. When applied to bleeding, these particles behave as molecular screen that fastly absorb the fluid and small molecular components of blood (molecular weight, $<40.000 \mathrm{Da}$ ), as a result of concentrating platelets, thrombin, fibrinogen, and other proteins on the outer surfaces of the particles. This localized dehydration of blood activates endogenous clotting processes and accelerates the development of a platelet fibrin plug $^{23,24}$. MPH has excellent efficacy for hemostasis, a rapidly cleared (by $\alpha$-amylaseat 6 or $12 \mathrm{~h}$ after its application) profile from the surgical site, and no negative effects on healing, such as fibrosis. Furthermore, it is shown that MPH reduces the incidence of surgical site infection ${ }^{23-25}$. It has been mostly used in surgeries on parenchymatous organs ${ }^{23,24}$, but there is no reports about the application of MPH after laminectomy for the prevention of EF. In the present study, we investigated the effect of MPH on fibrosis formation. Our results showed that the local application of MPH significantly diminished epidural scar formation and prevented arachnoidal involvement (control and $\mathrm{MPH} ; \mathrm{p}<0.05)$. In addition, we also found MPH treatment was associated with a significantly decreased number of fibroblast cells in the epidural scar formation at the laminectomy site (control and MPH; $p<0.05)$. This effect mostly related to its active hemostatic property. We can conclude that MPH can be applied safely for hemostasis in the case of ooze bleeding into the laminectomy site with the risk of postoperative EF.

Ankaferd Blood Stopper ${ }^{\circledR}$ (ABS) (Trend Teknoloji İlaç AS, Istanbul, Turkey) is a folkloric medicinal plant extract product, which has historically been used in Turkish practical medicine as a hemostatic agent ${ }^{26-30}$. It is a standardized mixture of the agent containing various ratios of five herbal extracts: Thymus vulgaris, Glycyrrhiza Glabra, Vitis Vinifera, Alpinia Officinarum, and Urtica Dioica. Each herb has effects on the endothelium, blood cells, angiogenesis, cell proliferation, and other physiologic mediators $^{26-29}$. It was shown that the ABS-induced network formation is related to the functions of blood proteins and red blood cells without destroying individual coagulation factors ${ }^{26-27}$. The basic mechanism of action for ABS is the formation of an encapsulated protein network that provides focal points for erythrocyte aggregation and forming a fibrin $\operatorname{plug}^{27,28}$. Previous studies have performed its safety, efficacy, sterility, and non-toxicity for external usage for hemostasis ${ }^{26-29}$. However, its effects on the formation of the fibrous tissue are still controversial. Some studies suggest that the topical application of ABS increased pericardial adhesion and fibrosis ${ }^{30}$. In another experimental study, ABS application did not increase intra-abdominal adhesion formation ${ }^{28}$. Our study demonstrated that the topical application of ABS did not increase EF after laminectomy in a rat model. Although the occurrence of fibrosis was statistically similar in both groups, the ABS-treated group showed a lower EF and AI score than the non-treated control group (For EF and AI, P value respectively: $0.135 ; 0.076)$. Furthermore, we also found significantly decreased number of fibroblast cells in the epidural scar formation with ABS treatment (control and ABS; $\mathrm{p}<0.05$ ). Our results were similar with the previous studies which demonstrated the decreasing of adhesion formation after ABS application for hemostasis in the intra-abdominal surgeries ${ }^{28}$. This beneficial effect is mostly related to the hemostatic and anti-inflammatory activity of ABS.

\section{Conclusions}

The topical application of microporous polysaccharide hemospheres and ankaferd blood stopper significantly reduces EF formation, dural adhesion and fibroblast cell density in an experimental rat laminectomy model. MPH and ABS, which have been previously used safely in humans for wound healing and parenchymatous organs hemostasis, "could be safely used for preventing epidural fibrosis after laminectomy in humans.

\section{References}

1. Fiume D, Sherkat S, Callovini GM, Parziale G, Gazzeri G. Treatment of the failed back surgery syndrome due to lumbo-sacral epidural fibrosis. Acta Neurochir. 1995;64(Suppl):116-8. PMID: 8748597.

2. North RB, Campbell JN, James CS, Conover-Walker MK, Wang H, Piantadosi S, Rybock JD, Long DM. Failed back surgery syndrome: 5-year follow-up in 102 patients undergoing repeated operation. Neurosurgery. 1991 May;28(5):685-90; discussion 690-1. PMID: 1831546

3. Loupasis GA, Stamos K, Katonis PG, Sapkas G, Korres DS, Hartofilakidis G. Seven- to 20-year outcome of lumbar discectomy. Spine (Phila Pa 1976).1999 Nov 15;24(22):2313-7. PMID: 10586454.

4. Lee JY, Ebel H, Friese M, Schillinger G, Schroder R, Klug N. Influence of TachoComb in comparison to local hemostyptic agents on epidural fibrosis in a rat laminectomy model. Minim Invasive Neurosurg. 2003 Apr;46(2):106-9. PMID: 12761682.

5. Robertson JT. Role of peridural fibrosis in the failed back: a review. Eur Spine J. 1996;5 (Suppl 1):S2-6. PMID: 8915643.

6. Sen O, Kizilkilic O, Aydin MV, Yalcin O, Erdogan B, Cekinmez M, Caner H, Altinors N. The role of closed-suction drainage in preventing epidural fibrosis and its correlation with a new grading 
system of epidural fibrosis on the basis of MRI. Eur Spine J. 2005;14(4):409-14. PMID: 15526220.

7. Kim SS, Michelsen CB. Revision surgery for failed back surgery syndrome. Spine (Phila Pa 1976). 1992 Aug;17(8):957-60. PMID: 1387978.

8. LaRocca H, Macnab I. The laminectomy membrane. Studies in its evolution, characteristics, effects and prophylaxis in dogs. J Bone Joint Surg Br. 1974 Aug;56B(3):545-50. PMID: 4421702.

9. Smith SA, Massie JB, Chesnut R, Garfin SR. Straight leg raising. Anatomical effects on the spinal nerve root without and with fusion. Spine (Phila Pa 1976). 1993 Jun;18(8):992-9. PMID: 8367787.

10. Silvers HR, Lewis PJ, Asch HL, Clabeaux DE. Lumbar diskectomy for recurrent disk herniation. J Spinal Disord. 1994 Oct;7(5):40819. PMID: 7819641.

11. Akkocaoglu M, Cehreli MC, Tekdemir I, Comert A, Guzel E, Dagdeviren A, Akca K. Primary stability of simultaneously placed dental implants in extraoral donor graft sites: a human cadaver study. J Oral Maxillofac Surg. 2007 Mar;65(3):400-7. PMID: 17307584.

12. He Y, Revel M, Loty B. A quantitative model of post-laminectomy scar formation. Effects of a nonsteroidal anti-inflammatory drug. Spine (Phila Pa 1976). 1995 Mar 1;20(5):557-63; discussion 57980. PMID: 7604325.

13. Canan S, Bozkurt HH, Acar M, Vlamings R, Aktas A, Sahin B, Temel Y, Kaplan S. An efficient stereological sampling approach for quantitative assessment of nerve regeneration. Neuropathol Appl Neurobiol. 2008 Dec;34(6):638-49. doi: 10.1111/j.13652990.2008.00938.x.

14. Ozay R, Uzar E, Aktas A, Uyar ME, Gurer B, Evliyaoglu O, Cetinalp $\mathrm{NE}$, Turkay $\mathrm{C}$. The role of oxidative stress and inflammatory response in high-fat diet induced peripheral neuropathy. J Chem Neuroanat. 2014 Jan;55:51-7. doi: 10.1016/j.jchemneu.2013.12.003.

15. Mirzai H, Eminoglu M, Orguc S. Are drains useful for lumbar disc surgery? A prospective, randomized clinical study. J Spinal Disord Tech. 2006 May;19(3):171-7. PMID: 16770213.

16. Cekinmez M, Erdogan B, Tufan K, Sarica FB, Ozen O, Caner $\mathrm{H}$. Is topical tissue plasminogen activator application effective on prevention of post-laminectomy epidural fibrosis? An experimental study. Neurol Res. 2009 Apr;31(3):322-6. doi: 10.1179/174313208X332940.

17. Ozkan U, Osun A, Samancioglu A, Ercan S, Firat U, Kemaloglu $\mathrm{S}$. The effect of bevacizumab and 5-Fluorouracil combination on epidural fibrosis in a rat laminectomy model. Eur Rev Med Pharmacol Sci. 2014;18(1):95-100. PMID: 24452949.

18. Wallwiener CW, Kraemer B, Wallwiener M, Brochhausen C, Isaacson KB, Rajab TK. The extent of adhesion induction through electrocoagulation and suturing in an experimental rat study. Fertil Steril. 2010 Mar 1;93(4):1040-4. PMID: 19147134.

19. Su C, Sui T, Zhang X, Zhang H, Cao X. Effect of topical application of mitomycin-C on wound healing in a postlaminectomy rat model: an experimental study. Eur J Pharmacol. 2012 Jan 5;674(1):7-12. PMID: 22056834.

20. Elliott-Lewis EW, Jolette J, Ramos J, Benzel EC. Thermal damage assessment of novel bipolar forceps in a sheep model of spinal surgery. Neurosurgery. 2010 Jul;67(1):166-71; discussion 171-2. PMID: 20568670.

21. Emmez H, Tonge M, Tokgoz N, Durdag E, Gonul I, Ceviker N. Radiological and histopathological comparison of microporous polysaccharide hemospheres and oxidized regenerated cellulose in the rabbit brain: a study of efficacy and safety. Turk Neurosurg. 2010 Oct;20(4):485-491. PMID: 20963698.

22. Ersoy G, Kaynak MF, Yilmaz O, Rodoplu U, Maltepe F, Gokmen $\mathrm{N}$. Hemostatic effects of microporous polysaccharide hemosphere in a rat model with severe femoral artery bleeding. Adv Ther. 2007 May;24(3):485-492. doi: 10.1007/BF02848770.

23. Ereth MH, Dong Y, Schrader LM, Henderson NA, Agarwal S, Oliver WC, Nuthall GA. Microporous Polysaccharide Hemospheres do not enhance abdominal infection in a rat model compared with gelatin matrix. Surg Infect (Larchmt). 2009 Jun;10(3):273-6. doi: 10.1089/sur.2007.033.

24. Humphreys MR, Castle EP, Andrews PE, Gettman MT, Ereth MH. Microporous polysaccharide hemospheres for management of laparoscopic trocar injury to the spleen. Am J Surg. 2008 Jan;195(1):99-103. PMID: 18070734.

25. Antisdel JL, Janney CG, Long JP, Sindwani R. Hemostatic agent microporous polysaccharide hemospheres (MPH) does not affect healing or intact sinus mucosa. Laryngoscope. $2008 \mathrm{Jul} ; 118(7)$ :12659. PMID: 18438268.

26. Karakaya K, Ucan HB, Tascilar O, Emre AU, Cakmak GK, Irkorucu $\mathrm{O}$, Ankarali H, Comert M. Evaluation of a new hemostatic agent Ankaferd Blood Stopper in experimental liver laceration. J Invest Surg. 2009 May-Jun;22(3):201-6. PMID: 19466658.

27. Goker H, Haznedaroglu IC, Ercetin S, Kirazli S, Akman U, Ozturk Y, Firat HC. Haemostatic actions of the folkloric medicinal plant extract Ankaferd Blood Stopper. J Int Med Res. 2008 JanFeb;36(1):163-70. PMID: 18304416

28. Comert M, Karakaya K, Barut F, Karadeniz Cakmak G, Ucan HB, Gultekin FA, Emre UA, Taşçılar O, Irkörücü O, Ankaralı H. Does intraabdominal use of Ankaferd Blood Stopper cause increased intraperitoneal adhesions? Ulus Travma Acil Cerr. 2010 Sep;16(5):383-9. PMID: 21038113.

29. Isler SC, Demircan S, Cakarer S, Cebi Z, Keskin C, Soluk M, Yuzbasioglu E. Effects of folk medicinal plant extract Ankaferd Blood Stopper on early bone healing. J Appl Oral Sci. 2010 July/ Aug;18(4):409-14. doi: 10.1590/S1678-77572010000400015.

30. Nazli Y, Colak N, Alpay MF, Haltas H, Aksoy ON, Akkaya IO, Cakır O. Assessment of the efficacy of Ankaferd blood stopper on the prevention of postoperative pericardial adhesions. Cardiovase J Afr. 2014 May-Jun;25(3):100-5. doi: 10.5830/CVJA-2014-011.

\section{Correspondence:}

Abit Aktaş

Istanbul University, Faculty of Veterinary Medicine, Department of Histology and Embryology

34320 Avc1lar Istanbul Turkey

Phone: 00905071016302

abit@istanbul.edu.tr

abitaktas@gmail.com

Received: Aug 22, 2015

Review: Oct 21, 2015

Accepted: Nov 19, 2015

Conflict of interest: none

Financial source: none

${ }^{1}$ Research performed at Department of Histology and Embryology, Faculty of Veterinary Medicine, Istanbul University, Turkey. 